\title{
Preservation of Buffalo Semen in Citric Acid Whey and Tris Buffer Extenders at $-196^{\prime} C$
}

\author{
R. Rajamahendran and L. Dharmasena \\ Deparinent of Animal Science, University of Peradeniya, Peradeniya, Sri Lanka
}

(Date of receipt: 22 March 1982)

(Date of acceptance: 17 April 1984)

\section{Introduction}

Our present population of local buffaloes is cstimated to be around 0.4 million. In order to meet our draught-power, milk and meat requirements the local buffalo population must be multiplied and upgraded to Indian River Buffalo standards. With this objective in mind, in 1967, large scale importation of Murvah and Surt: buffaloes were made from India and are maintained as a closed herd in state farms. Bull calves born in these farms are being issued to the farmers to upgrade their local animals. The genetic improvement achieved by this practice is very minimal. One of the quickest ways of achieving rapid genetic improvement is by artificial breeding. Artificial breeding in buffaloes is not practiced in Sri Lanka due to lack of trained and proven bulls for semen collection and further no work has been done on the evaluation of different diluents for the preservation of buffalo semen in Sri Lanka.

Recent studies on bufialo semen preservation at $4 \mathrm{C}^{6}$ and at room temperature, ${ }^{7}$ in Sri Lanka, indicate that buffalo semen could be preserved only upto 5 days with $50 \%$ motility. This problem of storage length could be overcome by storing semen in a good extender at $--196^{\circ} \mathrm{C}$ in liquid nitrogen. At this temperature semen could be kept for a number of years without affecting the motility and the conception rate in insemizated cows. A further advantage of deep frozen semen is that it is easy to handle and could be transported to any part of the island in liquid nitrogen. Citric acid whey, egg yolk citrate and TRIS buffer have been used as the diluents by the Indian animal scientists ${ }^{1}, 2$ for the preservation of buffalo semen at $-196^{\circ} \mathrm{C}$. In this study two diluents, citric acid whey and TRIS buffer were compared for their ability to preserve buffalo $\mathrm{s}$ imen at $-196^{\circ} \mathrm{C}$, under Sri Lanka conditions.

\section{Experimental}

\subsection{Animals and semen collection}

Four Murrahs, three Surtis and one indigenous buffalo belonging to the Department of Animal Husbandry of the University of Peradeniya, which were maintained under normal standard conditions of feeding and management, were used in this 
study. Semen was collected once a week from each bull using an artificial vagina and a dummy. A separate artificial vagina was used for each buffalo and this was designed to suit the bull. Warm water at a temperature of $40^{\circ} \mathrm{C}$ was poured outside the inner lining of the rubber tube and by inflating sufficient air optimum pressure was created to simulate a vagina of a cow in heat. In order to provide a smooth surface for the buffalo bull a lubricant namely a jelly or vasoline was applied at the mounting end of the artificial vagina. Animals after teasing were allowed to mount on a dummy and semen was collected by the operator into a graduated collection tube.

\subsection{Evaluation of samples}

Immediately after collection the colour, volume, wave pattern or mass movement, the general motility and the live and dead counts of sperms and abnormal sperms. were assessed. Evaluation for wave pattern or mass movement was done as follows. Two drops of each sample was kept on a slide, warmed to body temperature and viewed under the lowest power of the microscope for forward and progressive movement which simulates a wave motion in the sea. In order to evaluate the general motility a thin smear with a coverslip was viewed under the same powered lens of microscope. To ascertain the live and dead counts of sperms, Nigrosin and Eosin stained slides were used under the oil immersion lens of the microscope where the dead sperms were stained violet and the live sperms remained unstained. The abnormal sperms were determined in these stained preparations.

\subsection{Preparation of citric acid whey diluent and semen extension}

Citric acid whey packets supplied by the National Dairy Research Institute Karnal were used directly in the following way: Ten grams of citric acid whey with penicillin (1000 I.U. per $\mathrm{ml}$ of the diluent) and streptomycin (1 $\mathrm{mg}$ per $\mathrm{ml}$ of the diluent) were dissolved in $100 \mathrm{ml}$ of double distilled water. The suspension was allowed to stand for 5 - 10 minutes and filtered through cotton wool. The pH of this solution was adjusted to 6.8 with freshly prepared $10 \%$ sodium hydroxide solution. The solution thus prepared was divided into two equal fractions A and B. Glycerol was added to these fractions so that $3 \%$ of fraction $A$ and $11 \%$ of fraction $B$ constituted undiluted glycerol. Fresh semen was added to fraction $A$, keeping in mind after the final mixing of $\mathrm{A}$ and $\mathrm{B}$, the ratio of semen of the dilution be maintained at $1: 10$. Fractions $\mathrm{A}$ and $\mathrm{B}$ were cooled to $5^{\circ} \mathrm{C}$ in a refrigerator and part $\mathrm{B}$ was added to part $A$ in fractions at a time (about $1 / 5$ th of $B$ added to $A$ ) at an interval of $10-15$ minutes and the dilution was completed in 50-75 minutes.

\subsection{Preparation of TRIS diluent and semen extension}

In this preparation following chemicals were used: TRIS - $1.52 \mathrm{gms}$, citric acid $-0.85 \mathrm{gms}$, fructose $-0.625 \mathrm{gms}$. These were dissolved in $42.5 \mathrm{ml}$ of double distilled 
water. To $37.5 \mathrm{ml}$ of the above solution was added $10 \mathrm{ml}$ of egg yolk, $3 \mathrm{ml}$ of glycerol, penicillin (at the rate of 1000 I.U. per $\mathrm{ml}$ of the diluent) and streptomycin ( $1 \mathrm{mg}$ per $\mathrm{ml}$ of the diluent), mixed well, and $\mathrm{pH}$ was adjusted to 6.8. This was used as a single step diluent where $A$ and $B$ fractions were not involved. Here again, semen dilution rate was 1:10. Motility percent and live/dead sperm percent was assessed after extending the semen with citric acid whey and TRIS buffer.

\subsection{Equilibriation of extended semen}

This is the time taken by the extended semen at $5 \mathrm{C}$ to acquire the resistance power to cold shock. Normally it varies from $4-6$ hours. Hence the extended semen (with citric acid whey and TRIS buffer diluents) was kept in the refrigerator at $5^{\circ} \mathrm{C}$ for $4-6$ hours for equilibriation, after which time motility as well as live and dead count of sparmatozoa were assessed.

\subsection{Semen freezing}

The diluted semen samples after a period ( $4-6$ hours) of equilibriation were packed in ice, kept in a regiform box and transported by a vehicle to Central Artificial Insemination Centre, Kundasale, $16 \mathrm{~km}$ away from the place of collection. Diluted semen was tested for general motility, live and dead sperm counts, soon after transport. At the Artifial Insemination Centre the samples were kept inside a cold cabinet maintained in a temperature of $5^{\circ} \mathrm{C}$. Prior arrangements were made in such a way that all the equipment were sterilised and kept inside the cold cabinet so that all equipment required would attain a uniform temperature of $5^{\circ} \mathrm{C}$, to prevent any temperature shock to sperms. French ministraws of 0.25 cc.capacity were used for freezing semen. The straws were filled with diluted semen and the open end of the straws were dipped in polyvinyl powder to make a satisfactory seal. The straws were then placed in a water bath at $5^{\circ} \mathrm{C}$ for further equilibriation inside the cold cabinet for about 1 hour. Straws were held in bundles tabbed on the bottom of the water bath to remove excess powder, rolled and dried in absorbant towels. These straws were then kept in racks, made of stainless steel with a support, where the straws could be dried exposing all the surface and kept for half an hour at $5^{\circ} \mathrm{C}$. Once the straws were dried they were exposed to liquid nitrogen vapour (temperature, $-120^{\circ} \mathrm{C}$ ) at the junction between the neck and the body of the freezing tank. After seven minutes of cxposure the straws were lowered into liquid nitrogen.

\subsection{Assessment of frozen semen}

Aftcr fieezing the straws were transferred to a small liquid nitrogen tank and taken to the Department of Animal Husbanary Laboratory. Test straws were removed at 24 hrs and 96 hrs after freezing and thawed in warm water at $37^{\circ} \mathrm{C}$ for 12 seconds 
and assessed for motility and live/dead sperm percentage. In a separate study the motility and live/dead sperm percentage of thawed semen sampies were also determined at $0,2,4,6,8,10$ and 12 hrs after thawing.

\section{Results and Discussion}

A total of 86 collections were made from 8 bulls during the experimental period. However almost half of the collections could not be frozen due to the insufficient volume, low initial motility $(\leqslant 65 \%$, high dead sperm count $(20 \%)$ and due to other technical difficulties. In all 47 collections were frozen in TRIS and CAW diluents. The semen characteristics of the freshly collected semen are shown in Table 1. The motility value observed in our study is in agreement with the value of $65 \%$ xeported by Gill et al, 3 However, others have reported a higher initial motility of $81.5 \%$ in Murrah breeds. There was no significant breed effect on motility. Murrah breed gave the highest volume of semen. The value obtained for Murrah breed is in agreement with other reports. ${ }^{3}, 5$ The low value obtained in Surti and local buffalo can be due to the difference in age and body siza. There was no difierence in the concentration of sperms in Murrah and Surti senen. However, semen of local buffalo was watery, light in colour and recorded the lowest concentration. The concentration observed in this study was much higher than those reported by others.","

TAnLE I. Percentage of motile sperm, dead sperm percentage concentration and volume of freshily ejaculated semen

\begin{tabular}{lccccc}
\hline Breed & $\begin{array}{c}\text { No. of } \\
\text { samples }\end{array}$ & $\begin{array}{c}\text { Motility } \\
(\text { in } \%)\end{array}$ & $\begin{array}{c}\text { Dead sperms } \\
(\text { in \% })\end{array}$ & $\begin{array}{c}\text { Concentration } \\
\text { (in billion/ml })\end{array}$ & $\begin{array}{c}\text { Volume } \\
\text { (in ml })\end{array}$ \\
\hline Murrah & 23 & $70.1 \pm 1.8^{a}$ & $17.6 \pm 1.2^{a}$ & $4.47 \pm 03^{a}$ & $2.82 \pm 0.53^{a}$ \\
Surti & 17 & $68.1 \pm 2.6^{a}$ & $17.2 \pm 1.3^{a}$ & $3.58 \pm 0.4^{a}$ & $1.97 \pm 0.68^{b}$ \\
Local & 07 & $72.5 \pm 4.8^{a}$ & $25.7 \pm 4.5^{b}$ & $3.17 \pm 0.5^{b}$ & $1.98 \pm 0.34^{b}$ \\
\hline
\end{tabular}

Means bearing different superscripts within column are different $(\mathrm{P}<0.05)$

The percentage of motile sperms and dead sperms after dilution in TRIS and CAW diluent are shown in Table 2. There was no dilution or breed effect and again no difference in motility and dead sperm percentage were observed even after 6 hours of equilibriation in TRIS and CAW diluents (Table 3). However, there was a significant reduction in motility and increase in dead sperm percent after equilibriation. In this study the diluted semen samples after equilibriation were transported to a distant place (16 kilo metres away) for freezing. Motility and dead sperm percentage before and after transport of the diluted samples indicates no significant differences in these two parameters. This is of practical importance, as semen could be collected in one place, equilibriated and could be transported to another place in ice and freezing couk be done without affecting the semen quality. 
TABle: 2. Percentage of motile sperm and dead sperm after dilution of buffalo semen in TRIS and CAW diluent

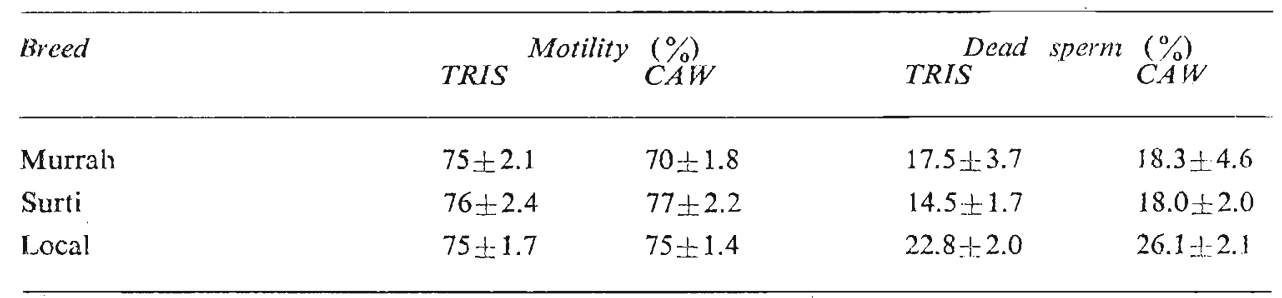

Data statistically not significant $(\mathrm{P}<0.05)$

TABLE 3. Percentage of motile sperm and dead sperm after equilibriation of buffalo semen in TRIS and CAW diluents

\begin{tabular}{llccc}
\hline Breed & \multicolumn{2}{c}{ Motility $(\%)$} & \multicolumn{2}{c}{ Dead sperm (\%) } \\
& TRIS & CAW & TRIS & CAW \\
\hline Murrah & $60.7 \pm 2.9$ & $56.7 \pm 4.9$ & $20.4 \pm 1.2$ & $22.5 \pm 0.8$ \\
Surti & $60.8 \pm 4.1$ & $61.8 \pm 3.1$ & $19.4 \pm 1.7$ & $24.2 \pm 1.0$ \\
Local & $62.8 \pm 4.2$ & $60.2 \pm 3.2$ & $21.4 \pm 1.4$ & $22.8 \pm 1.1$ \\
\hline
\end{tabular}

Data statistically not significant $(\mathrm{P}<0.05)$

The motility and dead sperm percentage of sperm in TRIS and CAW diluents after freezing are shown in Table 4 . There was significant reduction in sperm motility and elevation in percent dead sperms in both the diluents after freezing and thawing. However in TRIS diluent the reduction in motility was $27 \%$ compared to CAW where it was found to be $66 \%$. This observation is in agreement with the finding of Sharma et al. ${ }^{8}$ Therefore from this study it can be said that TRIS is a better diluent than CAW for the freezing of buffalo semen under Sri Lankan conditions. The effect of time on post thaw motility of buffalo sperm frozen in TRIS diluent is shown in Table 5. According to this observation frozen semen after thawing can be kept for a period of 6 hours under conditions prevailing in our country.

The fertility rate following insemination with frozen semen was tested in post-partum cows, in another study. The maximum fertility rate observed was only $35 \%$ and this low fertility was attributed to most of the animals not ovulating after hormonal treatment rather than to the quality of frozen semen. 


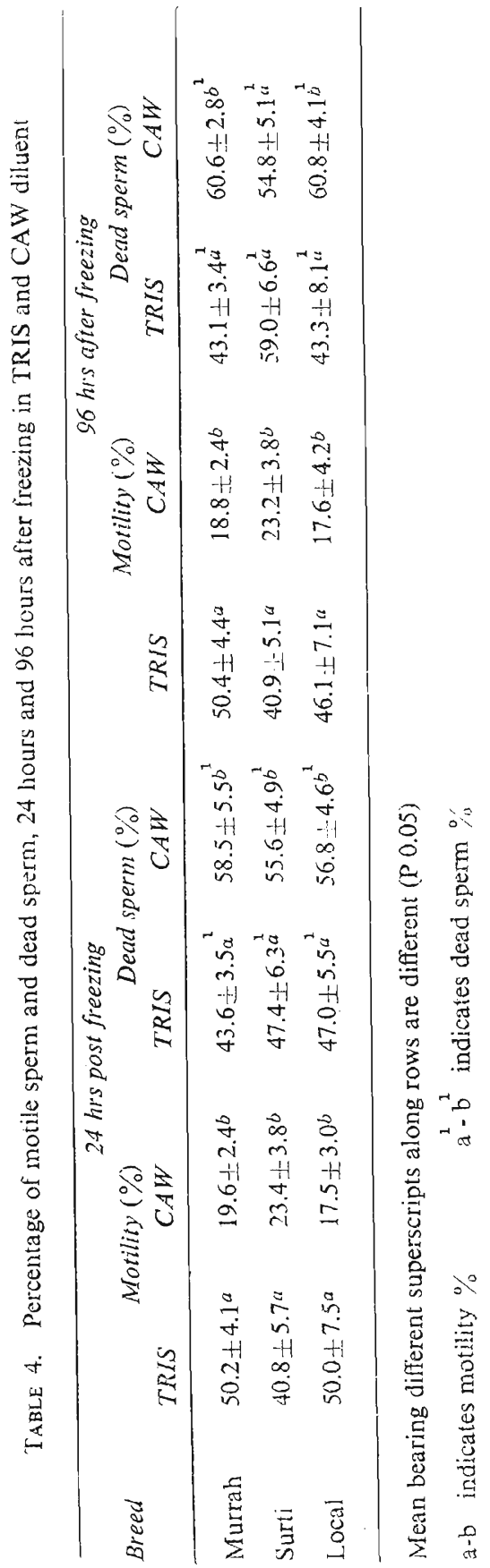


TABre 5. Effect of time on post thaw motility percentage of buffalo semen frezeñ in TRIS diluent

\begin{tabular}{lccccccc}
\hline Breed & 0 hrs & 2 irs & 4 hrs & 6 hrs & 8 hrs & 10 hrs & 12 hrs \\
\hline Murrah & $44^{*}$ & 44 & 42 & 37 & 34 & 7 & 4 \\
Surti & 46 & 53 & 55 & 49 & 28 & 1 & 6 \\
Local & 47 & 43 & 45 & 36 & 28 & 8 & 4 \\
Mean & 45 & 46 & 47 & 40 & 30 & 8 & 5 \\
\hline
\end{tabular}

$*$ number of observations $=10$

\section{Acknowledgements}

The authors gratefully acknowledge the assistance given in the form of research grant by the Department of Animal Production and Health and the Natural Resources, Energy and Science Authority of Sri Lanka. We also like to thank Drs. K. Balachandran and W. Marasinghe of the Artificial Insemination Centre, Kundasale for their assistance and co-operation.

\section{References}

1. Elimwadi, D. S., \& Kueprull Fluekrger, A. (1974). Froceedings of the XIX International Dairy Congress, New-Delhi, India, F.A.O. Report.

2. Gangul, N. C. (1978). Proceedings of Seminar on 'Reproduction and A.I. in Buffaloes'. National Dairy Research Institute, Karnal, India, December 4-15.

3. Gill, R. S., Gangwar, P. C. \& Yakkar, O. P. (1974). Indian J. Anim. Sci. 44: 415.

4. Kopalakrishnan, T. \& Rao, A. R. (1978). Indian Vet. J. 55:216.

5. Prabiu, S. S. \& Bhattacharya, P. (1951). Indian J. Vet. Sci. Anim. Husb. $21: 257$.

6. Rajamahendran, R., Thangarajah, P. \& Thangarajah, M. (1981). Ceylon Vet. J. 27:17.

7. Rajamahendran, R., Thangarajah, M. \& Thangarajai, P. (1981). J. Natm. Sci. Coum. Sri Lanka 9(2):149.

8. Silarma, A. K., Singh Sall, H., Elrmwadi, D. S. \& Fluekiger, A. (1979). Indian Vet. J. 56:1017.

9. VASANTH, J. K. (1978). Proceedings of Seminar on 'Reproduction and A.I. in Buffaloes'. National Dairy Research Institute, Karnal, India, Dec. 4-15. 